\title{
Factors Associated with Increases in Glucose Levels in the Perioperative Period in Non-Diabetic Patients
}

\author{
Vasanti Tilak, Catherine Schoenberg, Alejandro F. Castro III, Manasee Sant \\ Department of Anesthesiology and Perioperative Medicine, New Jersey Medical School, University of Medicine and Dentistry of \\ New Jersey, Newark, USA. \\ Email: vtilak@optonline.net
}

Received March $5^{\text {th }}, 2013$; revised April 19 $9^{\text {th }}, 2013$; accepted May $6^{\text {th }}, 2013$

Copyright (C) 2013 Vasanti Tilak et al. This is an open access article distributed under the Creative Commons Attribution License, which permits unrestricted use, distribution, and reproduction in any medium, provided the original work is properly cited.

\begin{abstract}
Background: Blood glucose levels are elevated during the perioperative period as a result of the neuro-endocrine response to the stress of surgery. In nondiabetic patients, blood glucose levels are not a part of routine preoperative testing nor are they monitored during surgery or in the post anesthesia care unit (PACU). We measured blood glucose levels in nondiabetic patients during the perioperative period to identify how many patients had high glucose levels and what factors were associated with increases in blood glucose levels. Methods: This prospective observational study included two hundred and ninety five nondiabetic patients between the ages of 18 and 80 years, undergoing elective noncardiac surgery. Blood glucose levels were measured preoperatively and at frequent, predetermined intervals during surgery and in the PACU. Patient characteristics, surgical and anesthetic factors, and pain scores in the PACU were recorded, as were postoperative complications. Results: Forty nine percent (49\%) of the patients had maximum intraoperative glucose levels of $126 \mathrm{mg} / \mathrm{dl}$ or higher and fifty three percent (53\%) had maximum postoperative glucose levels of 126 $\mathrm{mg} / \mathrm{dl}$ or higher. Preoperative glucose levels, family history of diabetes and amount of blood loss were statistically significantly associated with both max-intra-op and max-post-op glucose levels. Additionally, blood administration, surgery duration and race were significantly associated with max-intra-op glucose levels, while amount of intravenous fluids and sex were significantly associated with max-post-op glucose levels. Conclusion: A large number of nondiabetic patients in our study had maximum glucose levels $>126 \mathrm{mg} / \mathrm{dl}$ in the perioperative period. Certain patient characteristics, as well as surgical/anesthetic factors, were associated with increases in the glucose levels. More studies are indicated to determine which patients may benefit from glucose monitoring in the perioperative period.
\end{abstract}

Keywords: Blood Glucose; Perioperative; Nondiabetic

\section{Introduction}

Perioperative hyperglycemia has been recognized as one of the risk factors for increased morbidity and mortality after surgery. The majority of investigations have focused on diabetic patients undergoing cardiac surgery [1, 2] and/or on critically ill patients in intensive care units [3-5]. Blood glucose levels are not routinely monitored for nondiabetic patients during the perioperative period. In recent retrospective studies in patients undergoing noncardiac surgery, hyperglycemia has been linked with poor outcomes (increased length of stay, infectious complications and mortality) in patients without a history of diabetes $[6,7]$.

This is an exploratory study, focused on glucose levels during the perioperative period in non-diabetic patients undergoing noncardiac surgery. The study addresses two questions: How many patients have glucose levels above $126 \mathrm{mg} / \mathrm{dl}$ and what factors are associated with perioperative increase in glucose levels?

\section{Methods}

The study was registered at www.clinicaltrials.gov (NCT00468494). This prospective, cross sectional, observational study was approved by the IRB of the University of Medicine and Dentistry of New Jersey-New Jersey Medical School. All patients scheduled for surgery (all comers) were screened for potential enrollment between September 2006 and September 2008. Nondiabetic patients between 18 and 80 years of age undergoing elective surgery were included, after providing written informed consent, if their fasting blood glucose by finger stick on the day of surgery was less than $126 \mathrm{mg} / \mathrm{dl}$, as 
this is an accepted diagnostic value to exclude diabetes [8]. Patients who were pregnant or scheduled for cardiac surgery were excluded. Anesthetic management was at the discretion of the anesthesia providers. All patients received Lactated ringer's solution or normal saline as their primary intravenous (IV) fluid.

Blood glucose levels were recorded preoperatively, 15 minutes after induction, 15 minutes after incision, $15 \mathrm{mi}-$ nutes thereafter for 2 hours, then every 30 minutes until the end of surgery. The highest intraoperative glucose value for each patient was labeled as maximum intra-operative (max-intra-op) glucose. Blood glucose levels were also measured 30 minutes and 60 minutes after admission to the Post Anesthesia Care Unit (PACU). The highest glucose value in the PACU was labeled as maximum post-operative (max-post-op) glucose. Abbott Freestyle TM Freedom Blood Glucose Monitoring System (Abbott Diabetes Care, Abbott Park, IL 60064) was used for glucose measurements. The glucose meters were calibrated as per the manufacturer's recommendations. Blood samples for measurement were arterial (if an arterial line was placed by the anesthesia provider), venous (via a large bore venous catheter dedicated to glucose sampling), or capillary finger stick. Capillary finger stick was also used if the arterial line or dedicated intravenous catheter failed during the study period. The primary anesthesiologists were made aware of all glucose levels and were free to treat hyperglycemia or hypoglycemia. If intervention with insulin or glucose administration occurred, data collection was stopped. The glucose levels up to that point were included in the analysis.

Patient information, specifically demographic and intraoperative data and PACU pain scores [Visual Analogue Scale (VAS)] at 30 and 60 minutes after arrival, were recorded. Patient demographics recorded were: age, sex, race, height, weight, Body Mass Index (BMI), family history of diabetes, use of steroids or beta blockers on a regular basis and preoperative (pre-op) glucose levels. Intraoperative variables were: type of anesthesia, administration of midazolam before induction, induction agent, intraoperative steroids, amount of IV fluids administered (excluding blood), administration of blood, duration of anesthesia, duration of surgery and blood loss recorded on patient charts. Estimated blood loss was divided into three categories $(0-499 \mathrm{ml}, 500-999 \mathrm{ml}$ and $\geq 1000 \mathrm{ml})$. Total amount of opioid used was converted to the morphine equivalent. The Johns Hopkins Surgical Classification System was used to assign the surgical procedures to one of the five categories [9]. All patients were called two weeks after the procedure. A questionnaire was used to detect complications including wound infection, cardiac events, pulmonary complications, neurological complications or unplanned re-admission to the hospital.

This study was not designed to measure the incidence of postoperative complications as a function of perioperative hyperglycemia. That question would have required a much larger sample size. However, we did collect information on postoperative complications, which is presented in Table 1.

\section{Statistical Methods}

Data were analyzed with the Stata statistical package (ver. 12, StataCorp, College Station, TX). Descriptive analyses are presented as number (n) and percentage (\%), or as mean, standard deviation, median and range, as appropriate. Observations with missing values were documented and removed from the analysis. All continuous variables were assessed for normality and were transformed if they were not normally distributed. Age and pre-op glucose were normally distributed while max-intra-op and maxpost-op glucose levels, surgery duration, BMI, and the amount of IV fluid administered were log transformed. We explored various transformations for nonnormally distributed variables and used the log transformation, which was the best fit with best interpretability. Surgical procedure, sex, race, amount of blood loss and PACU pain scores were considered as categorical variables. Use of steroids or beta blockers on a regular basis, intra-operative steroid administration, family history of diabetes, midazolam administration before induction, and any blood administration were all considered binary variables (yes/ no). Pearson correlation and Student's t-test were used to investigate the bivariate association of continuous and binary variables respectively with log transformed maxintra-op and log transformed max-post-op glucose levels. ANOVA was used to determine the bivariate association of other categorical variables with multiple levels. Variables were assessed for multi-collinearity after transformation and before possible inclusion in multiple linear regression models.

Forward and backward stepwise multiple linear regressions were performed in order to determine the variables associated with log transformed max-intra-op and max-post-op glucose levels. The significance level for addition to, or removal from these models was set at $\mathrm{p}=$ 0.05 .

After the best models were determined, residuals were assessed for normality and homoscedasticity. Data was checked for outliers with possible undue leverage. Residuals were found to be normally distributed with little evidence of heteroscedasticity. Sensitivity analyses were performed to determine whether longer surgical duration led to increased max-intra-op glucose due to more sampling points. The first, second, third and fourth highest intra-operative glucose measurements were removed from each patient and the association was assessed each time. If the association were solely due to a larger sampling 
Table 1. Summary of patient statistics.

\begin{tabular}{|c|c|c|c|c|c|c|}
\hline Demographic variables & & & & & & \\
\hline & $\mathrm{n}$ & Mean & Std Dev & Median & Range & \\
\hline $\begin{array}{c}\text { Age (years) } \\
18-20 \\
21-30 \\
31-40 \\
41-50 \\
51-60 \\
61-70 \\
71-77\end{array}$ & $\begin{array}{c}295 \\
9 \\
29 \\
54 \\
91 \\
68 \\
30 \\
14\end{array}$ & 46.3 & 13.4 & 46 & $18-77$ & \\
\hline Height $(\mathrm{cm})$ & 291 & 167.3 & 10.4 & 167.6 & $142-193$ & \\
\hline Weight (kg) & 294 & 81.1 & 20.6 & 80 & $41-156$ & \\
\hline $\operatorname{BMI}\left(\mathrm{kg} / \mathrm{m}^{2}\right)$ & 291 & 29.1 & 7.1 & 27.7 & $17-62$ & \\
\hline Sex & Male & Female & Missing & & & \\
\hline $\mathrm{n}$ & 137 & 158 & 0 & & & \\
\hline$\%$ & $46 \%$ & $54 \%$ & $0 \%$ & & & \\
\hline Race & White & Black & Hispanic & Asian & Other & Missing \\
\hline $\mathrm{n}$ & 88 & 68 & 91 & 8 & 8 & 32 \\
\hline$\%$ & $30 \%$ & $23 \%$ & $31 \%$ & $3 \%$ & $3 \%$ & $11 \%$ \\
\hline Family history of diabetes & Yes & No & Missing & & & \\
\hline $\mathrm{n}$ & 89 & 182 & 24 & & & \\
\hline$\%$ & $30 \%$ & $62 \%$ & $8 \%$ & & & \\
\hline Beta-blocker usuage & Yes & No & Missing & & & \\
\hline $\mathrm{n}$ & 29 & 256 & 10 & & & \\
\hline$\%$ & $10 \%$ & $87 \%$ & $3 \%$ & & & \\
\hline Steroid usage & Yes & No & Missing & & & \\
\hline $\mathrm{n}$ & 20 & 264 & 11 & & & \\
\hline$\%$ & $7 \%$ & $89 \%$ & $4 \%$ & & & \\
\hline \multicolumn{7}{|l|}{ Intra-operative variables } \\
\hline & $\mathrm{n}$ & Mean & Std Dev & Median & Range & \\
\hline Surgery duration (minutes) & 279 & 173.7 & 105.6 & 143 & $38-790$ & \\
\hline IV fluids administered (ml) & 286 & 2202.1 & 1316.3 & 1900 & $400-8000$ & \\
\hline Anesthesia duration (minutes) & 283 & 245.1 & 121.3 & 215 & $92-898$ & \\
\hline Morphine equivalent dose (mg) & 295 & 32.4 & 22.7 & 30 & $0-125$ & \\
\hline Blood loss categories $(\mathrm{ml})$ & $<500$ & $500-999$ & $1000+$ & Missing & & \\
\hline $\mathrm{n}$ & 223 & 31 & 26 & 15 & & \\
\hline$\%$ & $76 \%$ & $11 \%$ & $9 \%$ & $5 \%$ & & \\
\hline Midazolam before induction & Yes & No & Missing & & & \\
\hline $\mathrm{n}$ & 253 & 29 & 13 & & & \\
\hline$\%$ & $86 \%$ & $10 \%$ & $4 \%$ & & & \\
\hline Steroid administration & Yes & No & & & & \\
\hline $\mathrm{n}$ & 28 & 267 & & & & \\
\hline$\%$ & $9 \%$ & $91 \%$ & & & & \\
\hline Blood administration & Yes & No & & & & \\
\hline $\mathrm{n}$ & 18 & 277 & & & & \\
\hline$\%$ & $6 \%$ & $94 \%$ & & & & \\
\hline Induction agent & Propofol & Etomidate & Missing & & & \\
\hline
\end{tabular}


Continued

\begin{tabular}{|c|c|c|c|c|c|c|}
\hline $\mathrm{N}$ & 265 & 9 & 21 & & & \\
\hline$\%$ & $90 \%$ & $3 \%$ & $7 \%$ & & & \\
\hline Anesthesia type & General & Neuraxial & Local w/sedation & & & \\
\hline $\mathrm{n}$ & 288 & 3 & 4 & & & \\
\hline$\%$ & $98 \%$ & $1 \%$ & $1 \%$ & & & \\
\hline John hopkins surgical procedure category & 1 (low) & 2 & 3 & 4 & 5 (high) & \\
\hline $\mathrm{n}$ & 13 & 105 & 139 & 34 & 4 & \\
\hline$\%$ & $4 \%$ & $36 \%$ & $47 \%$ & $12 \%$ & $1 \%$ & \\
\hline \multicolumn{7}{|l|}{ Post-operative variables } \\
\hline & $\mathrm{n}$ & Mean & Std Dev & Median & Range & \\
\hline Post anesthesia care unit pain score ( 30 minutes) & 274 & 5.8 & 3.5 & 6 & $0-10$ & \\
\hline Post anesthesia care unit pain score (60 minutes) & 269 & 5.3 & 3.3 & 6 & $0-10$ & \\
\hline Adverse outcomes & Cardiac & Pulmonary & Neurological & Infection & None & Missing \\
\hline $\mathrm{n}$ & 0 & 5 & 1 & 18 & 162 & 109 \\
\hline$\%$ & $0 \%$ & $2 \%$ & $0 \%$ & $6 \%$ & $55 \%$ & $37 \%$ \\
\hline \multicolumn{7}{|l|}{ Glucose variables } \\
\hline & $\mathrm{n}$ & Mean & Std Dev & Median & Range & \\
\hline Pre-operative glucose (mg/dl) & 295 & 96.5 & 13.2 & 97 & $62-125$ & \\
\hline Maximum intra-operative glucose (mg/dl) & 295 & 130.4 & 30.1 & 125 & $85-283$ & \\
\hline Maximum post-operative glucose (mg/dl) & 284 & 131.8 & 31.2 & 127 & $76-265$ & \\
\hline
\end{tabular}

frame, we would expect the association to be eliminated. This was not the case.

\section{Results}

Three hundred and eight patients were enrolled in the study. Ten subjects had fasting glucose levels above 126 $\mathrm{mg} / \mathrm{dl}$ on the day of surgery and were removed before data analysis. Three patients who had missing glucose values were also excluded. Results presented are for the remaining 295 patients.

Table 1 presents patient demographic characteristics and intraoperative surgical and anesthetic factors. The table also presents postoperative anesthesia care unit (PACU) pain scores, as well as max-intra-op and maxpost-op glucose readings. Although none of the patients had diabetes, a large number of them had blood glucose levels of $126 \mathrm{mg} / \mathrm{dl}$ or higher intraoperatively 49\%), as well as postoperatively (53\%) (Table 2 ).

We examined the relationship between max-intra-op glucose, and the demographic, surgical and anesthetic factors. We also examined the relationship of these factors and the PACU pain scores with max-post-op glucose. Though we had recorded many variables, we narrowed the list of variables included in the analyses. For example, we chose to exclude anesthesia duration because it was strongly correlated to surgery duration. We did not include the amount of opioids used because we had not recorded the timing of opioid administration and its temporal relationship with the maximum glucose levels. We also excluded the type of anesthesia and the induction agent used because the number of subjects in some categories was very small. Tables 3(a) and (b) show the association of the factors with max-intra-op and max-postop glucose. For step wise multiple linear regression we only included subjects with complete data on the characteristics of interest $(\mathrm{N}=204$ for max-intra-op model and $\mathrm{N}=198$ for max-post-op model). These characteristics were sex, age, race, log of BMI, preoperative glucose levels, preoperative use of beta blockers or steroids, family history of diabetes, Johns Hopkins surgical procedure category, midazolam administration before induction, log of surgery duration, estimated blood loss, log of IV fluids administered, intraoperative steroids and any blood administration. The PACU pain scores were considered for the max-post-op stepwise regression, even though there was not a statistically significant correlation in bivariate analysis $(p=0.60$ and 0.63 for pain scores at 30 minutes and 60 minutes respectively). The results of the forward and the backward stepwise procedures were identical for both max-intra-op and max-post-op glucose levels. Preop glucose levels, family history of diabetes and estimated blood loss were significantly associated with both max-intra-op and post-op glucose levels. Additionally, administration of blood, surgery duration and race had 
Table 2. Distribution of maximum glucose levels during peri-operative period.

\begin{tabular}{ccccc}
\hline & \multicolumn{2}{c}{ Intra operative } & \multicolumn{2}{c}{ Post operative } \\
\hline Maximum glucose levels & Number of patients & Percentage of patients & Number of patients & Percentage of patients \\
\hline$>200 \mathrm{mg} / \mathrm{dl}$ & 9 & $3 \%$ & 8 & $3 \%$ \\
181 to $200 \mathrm{mg} / \mathrm{dl}$ & 10 & $3 \%$ & 12 & $4 \%$ \\
161 to $180 \mathrm{mg} / \mathrm{dl}$ & 28 & $9 \%$ & 22 & $8 \%$ \\
141 to $160 \mathrm{mg} / \mathrm{dl}$ & 33 & $11 \%$ & 54 & $19 \%$ \\
126 to $140 \mathrm{mg} / \mathrm{dl}$ & 66 & $22 \%$ & 54 & $19 \%$ \\
$<126 \mathrm{mg} / \mathrm{dl}$ & 149 & $51 \%$ & 135 & $47 \%$ \\
\hline
\end{tabular}

Table 3. (a) Correlation of continuous variables with maximum glucose levels; (b) Bivariate association of categorical variables t-test and ANOVA.

(a)

\begin{tabular}{cccccccc}
\hline \multicolumn{3}{c}{ Maximum intra-operative glucose-log } & \multicolumn{4}{c}{ Maximum post-operative glucose-log } \\
\hline \multicolumn{2}{c}{ Pearson correlation coefficients } & \multicolumn{4}{c}{ Pearson correlation coefficients } \\
\hline Variable & R-value & p-value & N & Variable & R-value & p-value & N \\
\hline Surgery duration, log & 0.383 & 0.000 & 279 & IV fluid administered, log & 0.392 & 0.000 & 277 \\
IV fluids administered, log & 0.354 & 0.000 & 286 & Pre-operative glucose & 0.314 & 0.000 & 284 \\
Pre-operative glucose & 0.296 & 0.000 & 295 & Surgery duration, log & 0.301 & 0.000 & 270 \\
Age & 0.143 & 0.014 & 295 & Age & 0.168 & 0.005 & 284 \\
BMI, log & 0.024 & 0.687 & 291 & BMI, log & 0.089 & 0.139 & 280 \\
\hline
\end{tabular}

"R-value" is Pearson correlation coefficient, presented in descending order; "p-value" is significance level rounded to 3 decimal places (so 0.000 represents a value $<0.0005$ ); "N" is sample size.

(b)

\begin{tabular}{|c|c|c|c|c|c|c|c|c|c|}
\hline \multirow[b]{2}{*}{ Variable } & & \multicolumn{4}{|c|}{ Maximum intra-operative glucose ( $\log$ of) } & \multicolumn{4}{|c|}{ Maximum post-operative glucose (log of) } \\
\hline & & Mean & t-value & p-value & $\mathrm{N}$ & Mean & t-value & p-value & $\mathrm{N}$ \\
\hline \multirow{2}{*}{ Sex } & Male & 4.830 & 1.23 & 0.224 & 137 & 4.823 & 2.21 & 0.028 & 131 \\
\hline & Female & 4.861 & & & 158 & 4.883 & & & 153 \\
\hline \multirow{5}{*}{ Race } & Caucasian & 4.805 & 2.67 & 0.033 & 88 & 4.810 & 2.11 & 0.081 & 84 \\
\hline & African American & 4.918 & & & 68 & 4.908 & & & 67 \\
\hline & Hispanic & 4.840 & & & 91 & 4.875 & & & 87 \\
\hline & Asian & 4.818 & & & 8 & 4.878 & & & 8 \\
\hline & Other & 4.827 & & & 8 & 4.771 & & & 7 \\
\hline \multirow{2}{*}{ Family history of diabetes } & Yes & 4.882 & -2.11 & 0.036 & 89 & 4.891 & -1.93 & 0.055 & 86 \\
\hline & No & 4.822 & & & 182 & 4.833 & & & 175 \\
\hline \multirow{2}{*}{ Pre-operative beta blockers usage } & Yes & 4.832 & 0.35 & 0.724 & 29 & 4.858 & -0.11 & 0.915 & 29 \\
\hline & No & 4.847 & & & 256 & 4.854 & & & 247 \\
\hline \multirow{3}{*}{ Pre-operative steroids usage } & Yes & 4.857 & -0.24 & 0.815 & 20 & 4.875 & -0.44 & 0.661 & 20 \\
\hline & No & 4.845 & & & 264 & 4.852 & & & 255 \\
\hline & 1 & 4.653 & 8.04 & 0.000 & 13 & 4.671 & 10.66 & 0.000 & 13 \\
\hline \multirow{4}{*}{$\begin{array}{l}\text { Johns hopkins surgical procedure } \\
\text { category }\end{array}$} & 2 & 4.788 & & & 105 & 4.777 & & & 100 \\
\hline & 3 & 4.892 & & & 139 & 4.920 & & & 134 \\
\hline & 4 & 4.925 & & & 34 & 4.928 & & & 33 \\
\hline & 5 & 4.789 & & & 4 & 4.648 & & & 4 \\
\hline \multirow{3}{*}{ Midazolam before induction } & Yes & 4.842 & 2.08 & 0.038 & 29 & 4.848 & 2.15 & 0.032 & 29 \\
\hline & No & 4.927 & & & 253 & 4.944 & & & 245 \\
\hline & $<500$ & 4.817 & 15.72 & 0.000 & 223 & 4.834 & 7.02 & 0.001 & 216 \\
\hline \multirow[t]{2}{*}{ Blood loss } & $500-999$ & 4.944 & & & 31 & 4.954 & & & 30 \\
\hline & $1000+$ & 5.029 & & & 26 & 4.971 & & & 25 \\
\hline \multirow{2}{*}{ Blood administered } & Yes & 5.117 & -5.80 & 0.000 & 18 & 5.056 & -3.70 & 0.000 & 16 \\
\hline & No & 4.829 & & & 277 & 4.843 & & & 268 \\
\hline \multirow{2}{*}{ Intra-operative Steroids } & Yes & 4.880 & -1.10 & 0.277 & 28 & 4.911 & -1.36 & 0.176 & 28 \\
\hline & No & 4.844 & & & 267 & 4.849 & & & 256 \\
\hline
\end{tabular}

"t-value" is t-statistic from ANOVA; "p-value" is significance level rounded to 3 decimal places (so 0.000 represents a value $<0.0005$ ); "N" is sample size. 
statistically significant associations with max-intra-op glucose levels; and amount of IV fluids administered and sex were associated with max-post-op glucose levels (Tables 4 and 5).

For easier interpretation of the raw output we calculated the percentage change in glucose levels associated with the significant variables. An increment of $10 \mathrm{mg} / \mathrm{dl}$ in pre-operative glucose levels was associated with a 4.7\% (95\% CI: $2.8 \%-6.7 \%)$ increase in max-intra-op and $4.4 \%(95 \% \mathrm{CI}: 2.3 \%-6.5 \%)$ increase in max-postop glucose levels. A family history of diabetes was associated with a $7.4 \%$ (95\% CI: $1.6 \%$ - 13.4\%) increase in max-intra-op and $7.2 \%$ (95\% CI: $1.3 \%$ - 13.5\%) increase in max-post-op glucose levels. Patients with blood loss $\geq 1000 \mathrm{ml}$ had significantly higher max-intra-op (14.6\%; 95\% CI: $3.0 \%-27.6 \%$ ) and max-post-op (15.4\%; 95\% CI: $4.3 \%-27.7 \%$ ) glucose levels than those with a blood loss of $<500 \mathrm{ml}$. Blood administration during surgery was associated with a $16.4 \%(95 \% \mathrm{CI}: 3.3 \%-31.3 \%)$ increase in max-intra-op glucose levels. A doubling of the surgical duration was associated with a $5 \%(95 \% \mathrm{CI}$ : $1.2 \%-8.8 \%$ ) increase in max-intra-op glucose levels. African Americans and Hispanics had higher max-intraop glucose levels than White subjects. (7.9\%; CI: 1.1\% $15.2 \%$ and $9.1 \%$; CI: $2.6 \%$ - $16 \%$ respectively). There was a $6.2 \%(95 \%$ CI: $2.5 \%-10 \%)$ increase in max-postop glucose levels associated with doubling of the amount of IV fluids administered and max-post-op glucose levels were $6.4 \%(95 \% \mathrm{CI}: 0.8 \%-12.0 \%)$ higher in females compare to males.

\section{Discussion}

Among the patients in our study, 49\% had a max-intra-op glucose of $126 \mathrm{mg} / \mathrm{dl}$ or higher and $53 \%$ had a max-postop glucose of $126 \mathrm{mg} / \mathrm{dl}$ or higher. There is no consensus on the acceptable deviation in the glucose values in response to stress. Since this was an exploratory study we used a fasting level of $126 \mathrm{mg} / \mathrm{dl}$ as a reference to demonstrate the distribution of glucose levels in our subjects. This level was not used as a cut off, as all glucose levels were included in the regression analyses.

An increase in blood glucose levels during surgery is expected as part of the surgical stress response. Surgical injury can cause metabolic and hormonal changes resulting in hyperglycemia. The mechanisms involved in glucose homeostasis are complex. The contributing factors to perioperative hyperglycemia include a decrease in insulin secretion and an increase in insulin resistance; an increase in counter regulatory hormones; an increase in gluconeo genesis and a decrease in glucose utilization [1012]. A recent meta-analysis of 26 trials reporting mortality concluded that intensive insulin therapy did not improve mortality in critically ill patients admitted to intensive

Table 4. Regression model for maximum intra-operative glucose (log).

\begin{tabular}{|c|c|c|c|c|c|c|}
\hline $\mathrm{N}$ & 204 & & & & & \\
\hline $\mathrm{F}(10,193)$ & 10.8 & & & & & \\
\hline Prob $>$ F & 0.0000 & & & & & \\
\hline R-squared & 0.3589 & & & & & \\
\hline Adj R-squared & 0.3257 & & & & & \\
\hline & Coefficient & Std. Error & $\mathrm{t}$ & $P>|t|$ & \multicolumn{2}{|c|}{ [95\% Conf. interval] } \\
\hline Intercept & 3.9411 & 0.1571 & 25.09 & 0.000 & 3.6313 & 4.2509 \\
\hline Pre-operative Glucose in mg/dl & 0.0046 & 0.0010 & 4.85 & 0.000 & 0.0027 & 0.0065 \\
\hline Surgery duration in minutes $(\log )$ & 0.0697 & 0.0265 & 2.63 & 0.009 & 0.0174 & 0.1221 \\
\hline Family history of diabetes $(\mathrm{N}=0, \mathrm{Y}=1)$ & 0.0709 & 0.0278 & 2.55 & 0.011 & 0.0161 & 0.1257 \\
\hline Blood administered $(\mathrm{No}=0 \mathrm{Yes}=1)$ & 0.1516 & 0.0606 & 2.50 & 0.013 & 0.0321 & 0.2711 \\
\hline Blood loss (500 - $999 \mathrm{ml})$ & 0.0747 & 0.0459 & 1.63 & 0.105 & -0.0158 & 0.1652 \\
\hline Blood loss $(1000+\mathrm{ml})$ & 0.1364 & 0.0544 & 2.51 & 0.013 & 0.0291 & 0.2437 \\
\hline \multicolumn{7}{|l|}{ Race reference (Caucasian) } \\
\hline Race (African American) & 0.0760 & 0.0332 & 2.29 & 0.023 & 0.0106 & 0.1415 \\
\hline Race (Hispanic) & 0.0873 & 0.0311 & 2.81 & 0.006 & 0.0260 & 0.1487 \\
\hline Race (Asian) & -0.0719 & 0.0932 & -0.77 & 0.442 & -0.2557 & 0.1120 \\
\hline Race (Unknown) & 0.1607 & 0.1080 & 1.49 & 0.138 & -0.0523 & 0.3736 \\
\hline
\end{tabular}

Variables considered in this analysis were: sex, age, race, log of BMI, preoperative (pre-op) glucose levels, preoperative beta blockers, preoperative steroids, family history of diabetes, Johns Hopkins surgical procedure category, midazolam before induction, log of surgery duration, estimated blood loss, log of total intravenous fluids administered, intraoperative steroids and blood administration. 
Table 5. Regression model for maximum post-operative glucose (log).

\begin{tabular}{|c|c|c|c|c|c|c|}
\hline $\mathrm{N}$ & \multicolumn{2}{|c|}{198} & & & & \\
\hline $\mathrm{F}(6,191)$ & \multicolumn{2}{|c|}{14.17} & & & & \\
\hline Prob $>$ F & \multicolumn{2}{|c|}{0.0000} & & & & \\
\hline R-squared & \multicolumn{2}{|c|}{0.3081} & & & & \\
\hline Adj R-squared & \multicolumn{2}{|c|}{0.2863} & & & & \\
\hline & Coefficient & Std. error & $\mathrm{t}$ & $P>|t|$ & \multicolumn{2}{|c|}{ [95\% Conf. interval] } \\
\hline Intercept & 3.7051 & 0.2073 & 17.87 & 0.000 & 3.2962 & 4.1140 \\
\hline Pre-operative glucose in mg/dl & 0.0043 & 0.0010 & 4.16 & 0.000 & 0.0022 & 0.0063 \\
\hline IV fluids administered (log) & 0.0862 & 0.0259 & 3.33 & 0.001 & 0.0352 & 0.1371 \\
\hline \multicolumn{7}{|l|}{ Blood loss reference $(0$ - $499 \mathrm{ml})$} \\
\hline Blood loss (500 - 999 ml) & 0.1542 & 0.0483 & 3.19 & 0.002 & 0.0589 & 0.2494 \\
\hline Blood loss $(1000+\mathrm{ml})$ & 0.1432 & 0.0514 & 2.78 & 0.006 & 0.0417 & 0.2446 \\
\hline Family history of diabetes $(\mathrm{N}=0, \mathrm{Y}=1)$ & 0.0697 & 0.0289 & 2.42 & 0.017 & 0.0128 & 0.1266 \\
\hline Sex $($ Female $=1$, Male $=0)$ & 0.0623 & 0.0274 & 2.27 & 0.024 & 0.0082 & 0.1164 \\
\hline
\end{tabular}

Variables considered for this analysis were: sex, age, race, log of BMI, preoperative (pre-op) glucose levels, preoperative beta blockers, preoperative steroids, family history of diabetes, Johns Hopkins surgical procedure category, midazolam before induction, log of surgery duration, estimated blood loss, log of total intravenous fluids administered, intraoperative steroids, blood administration, and PACU pain scores.

care units (ICU), except for a subpopulation of patients admitted to surgical ICUs [13]. However, the acceptable perioperative glucose levels, the threshold for treatment with insulin, and the glucose levels associated with poor outcome are controversial. Various target glucose levels have been used in previous studies to titrate insulin administration. Van den Bergh et al. [3] targeted a blood glucose level (BG) of $80-110 \mathrm{mg} / \mathrm{dl}$, Krinsley et al. [4] targeted a BG $<140 \mathrm{mg} / \mathrm{dl}$ and the NICE-SUGAR study [5] had a range of $81-108 \mathrm{mg} / \mathrm{dl}$, in ICU patients while Lazar et al. [1] targeted a BG $125-200 \mathrm{mg} / \mathrm{dl}$ in patients undergoing coronary artery bypass graft. Different levels of glucose (mean and maximum) have also been used to compare patient outcomes, Frisch et al. [6] used a cutoff of $>150 \mathrm{mg} / \mathrm{dl}$ before and after surgery, and McGirt et al. [14] used $>200 \mathrm{mg} / \mathrm{dl}$ before surgery. However, glucose levels are not monitored routinely in nondiabetic patients during the perioperative period.

Stress induced hyperglycemia has been linked to poor outcomes in nondiabetics $[6,7,15]$. We have attempted to identify which patient characteristics and surgical/anesthetic factors are associated with increases in glucose levels. The direction and the degree of the association of different characteristics are shown in Tables $\mathbf{4}$ and $\mathbf{5}$.

Family history of diabetes, pre-op glucose levels and amount of blood loss were significantly associated with both max-intra-op and max-post-op glucose levels. Preop glucose levels showed a strong association with maxintra-op and max-post-op glucose $(\mathrm{p}<0.0005)$. An increment of $10 \mathrm{mg} / \mathrm{dl}$ in pre-operative glucose levels was associated with a $4.7 \%$ increase in max-intra-op and $4.4 \%$ increase in max-post-op glucose levels. ASA practice advisory does not recommend measuring glucose le- vels routinely during pre-op testing [16]. However, knowledge of patient's pre-op glucose may be useful in predicting the max-intra-op and max-post-op glucose levels.

A family history of diabetes had an unfavorable effect on glucose levels and was associated with a $7.4 \%$ increase in max-intra-op and $7.2 \%$ increase in max-postop glucose levels. Valdez et al. [17] have reported a significant independent association between family history of diabetes and prevalence of diabetes in the US population. Patients with a family history of diabetes in this study may be pre-diabetic or may have an altered glucose homeostasis.

Insulin resistance leading to hyperglycemia has been shown to be directly related to blood loss [18] and the type of surgical procedure [19-21]. In our study population, patients with blood loss $\geq 1000 \mathrm{ml}$ had significantly higher max-intra-op (14.6\%) and max-post-op (15.4\%) glucose levels than those with a blood loss of $<500 \mathrm{ml}$. We used Johns Hopkins Surgical Classification system [9] to categorize surgical procedures. It is possible that blood loss may be acting as a surrogate for the type of surgery. However, surgical category was not selected in the stepwise regressions and was non-significant even when forced into the final model.

Blood administration during surgery was associated with a $16.4 \%$ increase in max-intra-op glucose levels. The influence of the administration of blood might be attributable to a higher degree of stress, larger blood loss, or more surgical trauma. Another factor to consider is the amount of dextrose in banked blood. The citrate phosphate dextrose solution (CPD) contains 25.5 grams of dextrose per liter and the anticoagulant citrate dextrose solution (ACD) contains 22 grams of dextrose per liter. 
About $50 \mathrm{ml}$ of CPD, which has 1.23 grams of dextrose, is used for $450 \mathrm{ml}$ of blood. Patients receiving many units of blood can receive a significant dextrose load. Our findings differ from Cheng et al. [22] who studied glucose levels in pediatric patients undergoing liver transplantation and found no significant changes in the blood glucose levels in those receiving blood transfusion.

Surgical duration (log transformed) was significantly associated with increased max-intra-op glucose levels. A doubling of the surgical duration was associated with a $5 \%$ increase in max-intra-op glucose levels. For example, a surgery of 8 hours would lead to a $28 \%$ increase in max-intra-op glucose compared to a surgery of $15 \mathrm{~min}$ utes. We performed a sensitivity analysis, which showed that glucose readings of a single patient are not random over time but in fact are a function of time. This confirms that the sampling scheme, where longer surgical duration means more sample points, is not leading stochastically to high max-intra-op glucose levels. These findings differ from the review by Bower et al. [23] where glucose values peaked between 2 and 4 hours of surgery. Volatile anesthetics have been shown to cause hyperglycemia by impairing insulin release in rats [24]. All, except four patients in our study received inhalation agents, which may have been a contributing factor to the higher glucose levels observed.

African Americans and Hispanics had higher max-intra-op glucose levels than White subjects $(7.9 \%$ and $9.1 \%$ respectively). The relationship with other races was not significant. Cowie et al. [25] have described a higher incidence of diagnosed diabetes in non-Hispanic blacks and Mexican Americans compared to non-Hispanic whites, though the incidence of undiagnosed diabetes was similar. The amount of IV fluids administered (log transformed) and sex were additional factors significantly associated with max-post-op glucose levels. There was a $6.2 \%$ increase in max-post-op glucose levels associated with doubling of the amount of IV fluids administered. Little information is available about the effects of sex on the stress response and the evidence in the literature is inconclusive [26,27]. In our model, max-post-op glucose levels were $6.4 \%$ higher in females compared to males.

Previous studies in surgical patients have reported hyperglycemia in patients given steroids during surgery [28, 29]. In the present study, steroid administration during surgery was incorporated as a binary variable as the type of steroid and the dosages varied. In our patients steroid administration was not significantly associated with maximum glucose levels. This may be because the majority of patients received steroids toward the end of surgery for prevention of nausea.

Obese patients have been described to have altered glucose tolerance secondary to insulin resistance $[30,31]$. Mokdad et al. [32] have reported a strong association of
BMI with diabetes. However, BMI did not appear in our final model for max-intra or post-op-glucose, as significant. A family history of diabetes was correlated with BMI. The reason for BMI not entering the final model could be the stronger influence of family history of diabetes on glucose levels.

\section{Limitations}

Some methodological considerations of this study need to be mentioned. This was an exploratory observational study with multiple variables. The patient characteristics, the surgical procedures and the anesthetic management were not controlled.

The values for estimated blood loss were obtained from the anesthesia record. Given the difficulty in accurately measuring the blood loss, this finding will need to be validated in future studies.

The sample source for glucose measurement (arterial, venous, capillary) was not uniform among patients and sometimes not for the same patient. Previous work by Karon et al. [33] have shown that capillary whole blood glucose levels were similar to plasma glucose levels in the laboratory while arterial and venous whole blood glucose levels were higher. Rice et al. [34] have discussed the inaccuracies of point of care devices in the perioperative setting. We did not take into account these factors while analyzing the data.

The results about the patient characteristics, surgi$\mathrm{cal} /$ anesthetic factors and the quantitative values need to be interpreted cautiously. Since this was an exploratory investigation we chose to include many variables. Some of the variables that showed significance may be surrogates for others. More studies will be needed to separate out the independent predictive values of each variable.

\section{Conclusion}

We found certain factors associated with high glucose levels in the perioperative period in nondiabetic patients. Pre-op glucose levels, family history of diabetes and amount of blood loss were associated with both maxintra and post-op glucose levels; blood administration, surgical duration and race with max-intra-op glucose levels; and amount of IV fluids and gender with max-post-op glucose levels. We hope that these findings generate interest in further research to identify risk factors for intraoperative hyperglycemia.

\section{REFERENCES}

[1] H. L. Lazar, S. R. Chipkin, C. A. Fitzgerald, Y. Bao, H. Cabral and C. S. Apstein, "Tight Glycemic Control in Diabetic Coronary Artery Bypass Graft Patients Improves Perioperative Outcomes and Decreases Recurrent Ischemic Events," Circulation, Vol. 109, No. 12, 2004, pp. 1497 - 
1502. doi:10.1161/01.CIR.0000121747.71054.79

[2] A. Ouattara, P. Lecomte, M. Y. Le, M. Landi, S. Jacqueminet, I. Platonov, et al., "Poor Intraoperative Blood Glucose Control Is Associated with a Worsened Hospital Outcome after Cardiac Surgery in Diabetic Patients," Anesthesiology, Vol. 103, No. 4, 2005, pp. 687-694. doi:10.1097/00000542-200510000-00006

[3] G. van den Berghe, P. Wouters, F. Weekers, C. Verwaest, F. Bruyninckx, M. Schetz, et al., "Intensive Insulin Therapy in Critically Ill Patients," New England Journal of Medicine, Vol. 345, No. 19, 2001, pp. 1359-1367.

[4] J. S. Krinsley, "Effect of an Intensive Glucose Management Protocol on the Mortality of Critically Ill Adult Patients," Mayo Clinic Proceedings, Vol. 79, No. 8, 2004, pp. 992-1000. doi:10.4065/79.8.992

[5] The Nice-Sugar Study Investigators. "Intensive versus Conventional Glucose Control in Critically Ill Patients," New England Journal of Medicine, Vol. 360, No. 13, 2009, pp. 1283-1297. doi:10.1056/NEJMoa0810625

[6] A. Frisch, P. Chandra, D. Smiley, L. Peng, M. Rizzo, C. Gatcliffe, et al., "Prevalence and Clinical Outcome of Hyperglycemia in the Perioperative Period in Non Cardiac Surgery," Diabetes Care, Vol. 33, No. 8, 2010, pp. 17831788. doi:10.2337/dc10-0304

[7] S. Kwon, R. Thompson, P. Dellinger, D. Yanez, E. Farrohki and D. Flum, "Importance of Perioperative Glycemic Control in General Surgery: A Report from the Surgical Care and Outcomes Assessment Program," Annals of Surgery, Vol. 257, No. 1, 2013, pp. 8-14. doi:10.1097/SLA.0b013e31827b6bbc

[8] American Diabetes Association. "Report of the Expert Committee on the Diagnosis and Classification of Diabetes Mellitus," Diabetes Care, Vol. 26, No. 1, 2003, pp. S5S20.

[9] L. R. Pasternak, "Preanesthesia Evaluation of the Surgical Patient," ASA Refresher Courses in Anesthesiology, Vol. 24, 1996, pp. 205-219. doi:10.1097/00126869-199624000-00016

[10] J. P. Desborough, "The Stress Response to Trauma and Surgery," British Journal of Anesthesiology, Vol. 85, No. 1, 2000, pp. 109-117. doi:10.1093/bja/85.1.109

[11] S. Akhtar, P. G. Barash and S. E. Inzucchi, "Scientific Principles and Clinical Implications of Perioperative Glucose Regulation and Control," Anesthesia \& Analgesia, Vol. 110, No. 2, 2010, pp. 478-497. doi:10.1213/ANE.0b013e3181c6be63

[12] A. K. Lipshutz and M. A. Gropper, "Perioperative Glycemic Control," Anesthesiology, Vol. 110, No. 2, 2009, pp. 408-421.

[13] D. E. Griesdale, R. J. de Souza, R. M. van Dam, D. K. Heyland, D. J. Cook, A. Malhotra, et al., "Intensive Insulin Therapy and Mortality among Critically Ill Patients: A Meta-Analysis including NICE-SUGAR Study Data," Canadian Medical Association Journal, Vol. 180, No. 8, 2009, pp. 821-827. doi:10.1503/cmaj.090206

[14] M. J. McGirt, G. F. Woodworth, B. S. Brooke, A. L. Coon, S. Jain, D. Buck, et al., "Hyperglycemia Independently Increases the Risk of Perioperative Stroke, Myocardial
Infarction, and Death after Carotid Endarterectomy," Neurosurgery, Vol. 58, No. 14, 2006, pp. 1066-1073. doi:10.1227/01.NEU.0000215887.59922.36

[15] M. Y. Rady, D. J. Johnson, B. M. Patel, J. S. Larson and R. A. Helmers, "Influence of Individual Characteristics on Outcome of Glycemic Control in Intensive Care Unit Patients with or without Diabetes Mellitus," Mayo Clinic Proceedings, Vol. 80, No. 12, 2005, pp. 1558-1567. doi: $10.4065 / 80.12 .1558$

[16] ASA Committee, "Statement on Routine Preoperative Laboratory and Diagnostic Testing: Standards and Practice Parameters Amended on October 22," 2008.

[17] R. Valdez, P. W. Yoon, T. Liu and M. J. Khoury, "Family History and Prevalence of Diabetes in the US Population," Diabetes Care, Vol. 30, No. 30, 2007, pp. 2517-2522. doi: $10.2337 / \mathrm{dc} 07-0720$

[18] A. Thorell, J. Nygren and O. Ljungqvist, "Insulin Resistance: A Marker of Surgical Stress," Current Opinion in Clinical Nutrition and Metabolic Care, Vol. 2, No. 1, 1999, pp. 69-78. doi:10.1097/00075197-199901000-00012

[19] A. Thorell, S. Efendic, M. Gutniak, T. Haggmark and O. Ljungqvist, "Insulin Resistance after Abdominal Surgery," British Journal of Surgery, Vol. 81, No. 1, 1994, pp. 5963. doi:10.1002/bjs. 1800810120

[20] T. Schricker, A. Berroth, U. Pfeiffer, M. Schreiber, E. Malik, M. Schmidt, et al., "Influence of Vaginal versus Abdominal Hysterectomy on Perioperative Glucose Metabolism," Anesthesia \& Analgesia, Vol. 83, No. 5, 1996, pp. 991-995. doi:10.1213/00000539-199611000-00016

[21] A. Thorell, J. Nygren, P. Essen, M. Gutniak, A. Loftenius, B. Andersson and O. Ljungqvist, "The Metabolic Response to Cholecystectomy: Insulin Resistance after Open Compared with Laparoscopic Operation," European Journal of Surgery, Vol. 162, No. 3, 1996, pp. 187-191.

[22] K. W. Cheng, C. L. Chen, Y. F. Cheng, C. C. Tseng, C. H. Wang, Y. S. Chen, et al., "Dextrose in the Banked Blood Products Does Not Seem to Affect the Blood Glucose Levels in Patients Undergoing Liver Transplantation," World Journal of Gastroenterology, Vol. 11, 2005, pp. 2789-2791.

[23] W. F. Bower, P. Y. Lee, A. P. Kong, J. Y. Jiang, M. J. Underwood, J. C. Chan, et al., "Peri-Operative Hyperglycemia: A Consideration for General Surgery?" American Journal of Surgery, Vol. 199, No. 2, 2010, pp. 240-248. doi:10.1016/j.amjsurg.2009.04.010

[24] C. J. Zuurbier, P. J. Keijzers, A. Koeman, H. B. Van Wezel and M. W. Hollmann, "Anesthesia's Effects on Plasma Glucose and Insulin and Cardiac Hexokinase at Similar Hemodynamics and without Major Surgical Stress in Fed Rats," Anesthesia \& Analgesia, Vol. 106, No. 1, 2008, pp. 135-142. doi:10.1213/01.ane.0000297299.91527.74

[25] C. C. Cowie, K. F. Rust, E. S. Ford, M. S. Eberhardt, D. D. Byrd-Holt, C. Li, D. E. Williams, et al., "Full Accounting of Diabetes and Pre-Diabetes in the US Population in 1988-1994 and 2005-2006," Diabetes Care, Vol. 32, No. 2, 2009, pp. 287-294. doi:10.2337/dc08-1296

[26] D. Jezová, E. Juránková, A. Mosnárová, M. Kriska and I. Skultétyová, "Neuroendorcine Response during Stress with Relation to Gender Differences," Acta Neurobiologiae 
Experimentalis (Wars), Vol. 56, 1996, pp. 779-785.

[27] B. M. Kudielka, D. H. Hellhammer and S. Wüst, "Why Do We Respond So Differently? Reviewing Determinants of Human Salivary Cortisol Responses to Challenge," Psychoneuroendocrinology, Vol. 34, No. 1, 2009, pp. 218. doi:10.1016/j.psyneuen.2008.10.004

[28] P. Hans, A. Vanthuyne, P. Y. Dewandre, J. F. Brichant and V. Bonhomme, "Blood Glucose Concentration Profile after $10 \mathrm{mg}$ Dexamethasone in Non-Diabetic and Type 2 Diabetic Patients Undergoing Abdominal Surgery," British Journal of Anesthesiology, Vol. 97, No. 4, 2006, pp. 164-170. doi:10.1093/bja/ael111

[29] M. B. Lukins and P. H. Manninen, "Hyperglycemia in Patients Administered Dexamethasone for Craniotomy," Anesthesia \& Analgesia, Vol. 100, No. 4, 2005, pp. 11291133. doi:10.1213/01.ANE.0000146943.45445.55

[30] J. A. Martyn, M. Kaneki and S. Yasuhara, "Obesity-Induced Insulin Resistance and Hyperglycemia: Etiologic Factors and Molecular Mechanisms," Anesthesiology, Vol. 109, No. 1, 2008, pp. 137-148. doi:10.1097/ALN.0b013e3181799d45
[31] B. B. Kahn and J. S. Flier, "Obesity and Insulin Resistance," Journal of Clinical Investigation, Vol. 106, No. 4, 2000, pp. 473-481. doi:10.1172/JCI10842

[32] A. H. Mokdad, E. S. Ford, B. A. Bowman, W. H. Dietz, F. Vinicor, V. S. Bales, et al., "Prevalence of Obesity, Diabetes, and Obesity-Related Health Risk Factors 2001," Journal of American Medical Association, Vol. 289, No. 1, 2003, pp. 76-79. doi:10.1001/jama.289.1.76

[33] B. S. Karon, G. Y. Gandhi, G. A. Nuttall, S. C. Bryant, H. V. Schaff, M. M. McMahon, et al., "Accuracy of Roche Accu-Chek Inform Whole Blood Capillary, Arterial, and Venous Glucose Values in Patients Receiving Intensive Intravenous Insulin Therapy after Cardiac Surgery," American Journal of Clinical Pathology, Vol. 127, No. 6, 2007, pp. 919-926. doi:10.1309/6RFQCKAAJGKWB8M4

[34] M. J. Rice, A. D. Pitkin and D. B. Coursin, "Review Article: Glucose Measurement in the Operating Room: More Complicated than It Seems," Anesthesia \& Analgesia, Vol. 110, No. 4, 2010, pp. 1056-1065. 